\title{
Experiences with cutaneous ureterostomies in adults
}

\author{
W. M. LIEN* \\ M.B., Ch.B., F.R.C.S. \\ Dudley Road Hospital, Birmingham
}

\begin{abstract}
Summary
Between 1963 and 1971, twenty-five adult patients underwent cutaneous ureterostomies. The operation was performed for neurogenic bladder in sixteen cases, malignant diseases in eight cases and congenital bladder neck obstruction in one case. Sixteen patients were alive and well at the time of writing. The followup period ranged between 5 days and 7 years. The results were analysed and advantages of this type of urinary diversion discussed.
\end{abstract}

\section{Introduction}

Cutaneous ureterostomy has been known to surgeons for a very long time but, on the whole, it has not achieved popularity. Its use as an operation for urinary diversion in childhood has been documented in the literature on numerous occasions, for example by Eckstein (1963), Rickham (1964), Williams and Rabinovitch (1967) and Eckstein and Kapila (1970). However, reports of unmodified form of cutaneous ureterostomy in adults have been scanty. Straffon, Kyle and Corvalan (1969) reported their results in five patients and Feminella Jr and Lattimer (1971) published a series of seventy cases.

In this paper, experiences with cutaneous ureterostomies in twenty-five adult patients are reported.

\section{Material and methods}

Twenty-five cases of cutaneous ureterostomies were performed between 1963 and 1971. These patients were all admitted under the care of one consultant surgeon (Mr D. St Clair L. Henderson) in a large regional hospital. There were sixteen patients with neurogenic bladder; all were transferred from Robert Jones and Agnes Hunt Orthopaedic Hospital, Oswestry, for their operations and immediate after care. Spina bifida, traumatic paraplegia and tetraplegia were the underlying conditions in these cases. In eight patients, the operations were performed for malignancy, the primary tumour being situated at the bladder, rectum or cervix. Five out of these eight patients had received radiotherapy previously. There was one case of congenital bladder neck obstruction with bilateral hydronephrosis and

* Correspondence: Mr W. M. Lien, Good Hope General Hospital, Rectory Road, Sutton Coldfield, Warwickshire B75 7RR. hydroureters; cutaneous ureterostomies were carried out for progressive deterioration of renal function.

The age of the patients at the time of operation ranged between 11 and 77 years (mean 38.5 years). There were twenty men and five women, giving a male/female sex ratio of $4: 1$. The follow-up period ranged between 5 days and 7 years (mean 3.5 years). Sixteen patients had bilateral, while eight had unilateral cutaneous ureterostomy. In all, forty-one ureterostomies were performed on twenty-five patients.

\section{Technique of operation}

All operations were performed under general anaesthesia. The abdomen was opened through a lower mid-line incision and the ureters approached extraperitoneally. After mobilization, the ureters were ligated and divided as low down as possible. A disc of skin and external oblique fascia $1.5 \mathrm{~cm}$ in diameter were excised and the muscle and peritoneal layers perforated with blunt forceps. The upper end of each divided ureter, with an indwelling polyvinyl whistle tip catheter extending to the renal pelvis, was then brought out into the iliac fossa. No attempt was made to form a spout or to make a skin pedicle flap. The mucosa of the ureter was sutured to the skin. After exteriorization, the ureter was flush with the skin surface of the abdominal wall. The extraperitoneal spaces were drained. The ureteric catheters were removed on the seventh post-operative day and bags were fitted onto the abdominal wall.

\section{Results}

The distribution and fate of the twenty-five patients who underwent cutaneous ureterostomies are shown in Table 1. Sixteen patients are alive and well at the

TABle 1. Distribution and fate of twenty-five patients with cutaneous ureterostomies

\begin{tabular}{llccccc}
\hline Group & $\begin{array}{c}\text { Primary } \\
\text { pathology }\end{array}$ & $\begin{array}{c}\text { No. of } \\
\text { cases }\end{array}$ & Dead & Alive & Improved & Same \\
\hline I & Neurogenic & 16 & 6 & 10 & 10 & 0 \\
II & Malignant & 8 & 3 & 5 & 3 & 2 \\
III & Congenital & 1 & 0 & 1 & 1 & 0 \\
\multicolumn{2}{l}{ Total } & 25 & 9 & 16 & 14 & 4 \\
\hline
\end{tabular}


time of writing. They have been followed up and assessed clinically, radiologically and biochemically on intravenous pyelograms and blood urea estimations. Five patients who are alive belong to Group II; three of these have shown improvement while in the other two cutaneous ureterostomies have halted the deterioration of renal function though there has not been any overall improvement. The only patient in Group III has improved. No one who is living has been made worse by surgery.

In five patients, the ureterostomies require intubation or regular dilatation because of ureteropelvic obstruction or stricture formation. In four of these patients only one side was affected. The only other complication encountered was difficulty in fitting a collecting appliance in one patient.

There were nine deaths, five from renal failure, three from carcinomatosis and one from bronchopneumonia. Table 2 shows the number of deaths in each group. At the time of death, amyloid disease had developed in two patients.

TABLE 2. Cause of death after cutaneous ureterostomies

\begin{tabular}{lcccc}
\hline $\begin{array}{c}\text { Primary } \\
\text { pathology }\end{array}$ & $\begin{array}{c}\text { No. of } \\
\text { deaths }\end{array}$ & $\begin{array}{c}\text { Renal } \\
\text { failure }\end{array}$ & $\begin{array}{c}\text { Carcino- } \\
\text { matosis }\end{array}$ & Others \\
\hline Neurogenic & 6 & 5 & 0 & 1 \\
Malignant & 3 & 0 & 3 & 0 \\
\hline
\end{tabular}

\section{Discussion}

Cutaneous ureterostomy offers a simple, effective method of supravesical urinary diversion. It has not attained popularity because the operation is often done too late, followed inevitably by poor results. These late cases are often due to the reluctance to accept a form of urinary diversion on the patient's part. Figures 1, 2 and 3 show the intravenous pyelo-

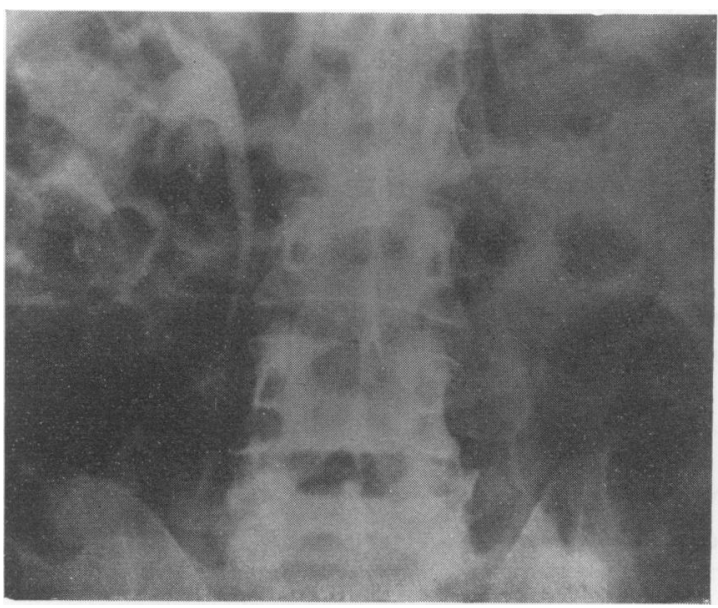

FIG. 1. Five-minute film of intravenous pyelogram before bilateral cutaneous ureterostomies, showing delayed renal function on the left.

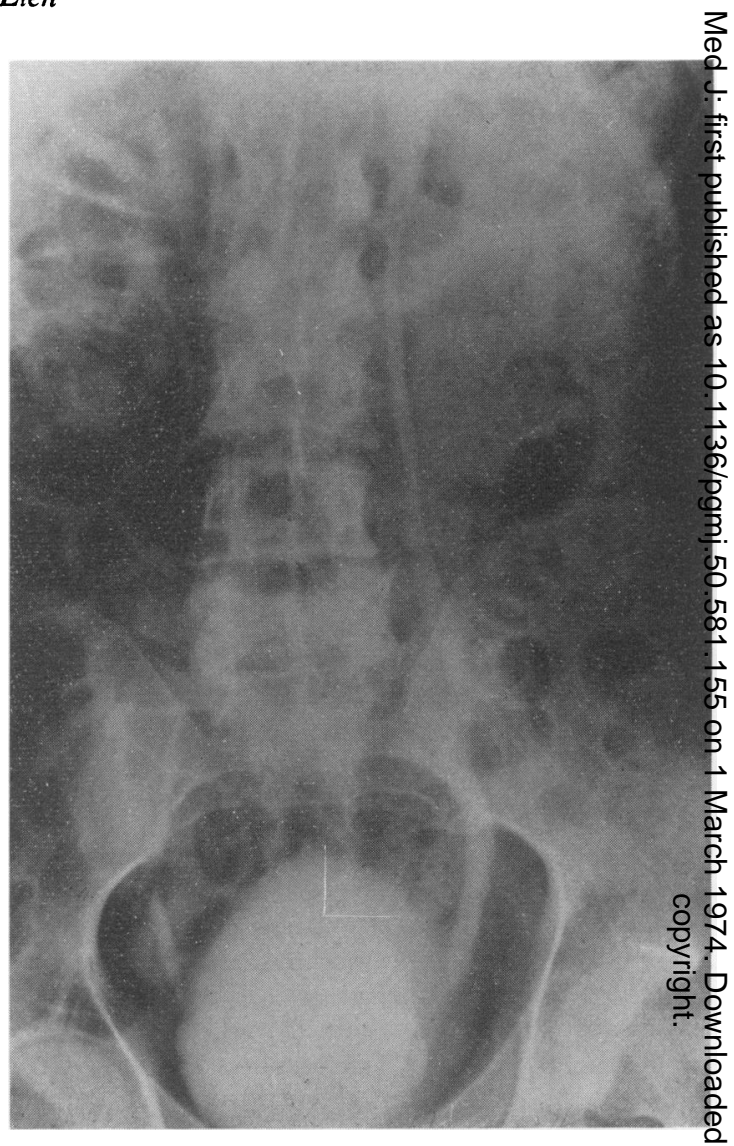

FIG. 2. Same patient as Fig. 1. Fifty-minute film of intravenous pyelogram before bilateral cutaneous ureterostomies, showing some calyceal dilatation and a rather full ureter on the left.

grams of a patient before and after cutareous ureterostomies, illustrating that the result can be rewarding in properly selected cases.

Ureterosigmoidostomy has its well-recognized complications of electrolyte disturbance and an in creased incidence of tumour formation at the anasto motic sites; rectal continence is also essentiaf Ureteroileostomy gives rise to much less complicap tions but is nevertheless a much bigger operative procedure than cutaneous ureterostomy. The ileall loop not infrequently undergoes stenosis or prōlapse. It is often argued that one external stoma is preferable to two, but the patient has to empty the bag twice as often. If obstruction should develop aq the uretero-colic anastomosis in a colonic conduit of uretero-ileal anastomosis in an ileal conduit, the obstructed ureter can easily be brought to the surface as a cutaneous ureterostomy, no further anastomosis between it and the bowel being necessary.

A serious disadvantage of cutaneous ureterostomy has been the high incidence of stricture formation? 


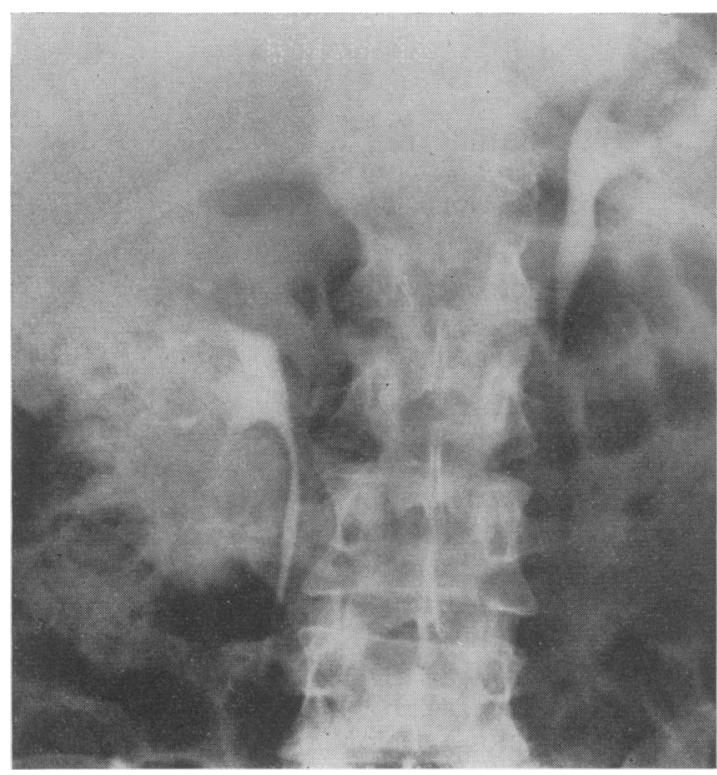

FIG. 3. Five-minute film of intravenous pyelogram after bilateral cutaneous ureterostomies, showing that the upper urinary tracts have returned to normal.

Feminella $\mathrm{Jr}$ and Lattimer (1971) reviewed seventy cases and found that the incidence of stricture was $64 \%$, a figure comparable to other series. In the obstructed dilated ureter, a sufficient length can be mobilized without jeopardizing its blood supply and a good stoma can be made. Stricture formation occurred in five out of twenty-five patients in this series and in four patients only one ureter was affected. This is a much lower incidence than that previously reported.

Another reason responsible for the unpopularity of cutaneous ureterostomy has been the difficulty in fitting the patients with a good collection device in the past. This problem has now been overcome. The patients reported in this series are fitted with disposable or formal rubber ileostomy bags, whichever is more suitable for the individual. In one patient who was particularly hirsute, some difficulty was experienced with fitting an appliance until the skin was constantly kept shaved.
During the follow-up of patients with cutaneous ureterostomies, a watch should be kept for recurrent infection developing within the disconnected bladder, as in patients with ureteroileostomies. Periodic bladder washouts may be necessary and in troublesome cases cystectomy may be required.

The advantages of cutaneous ureterostomy are therefore as follows.

(1) It is a simple and less traumatic form of urinary diversion when compared with ureterosigmoidostomy and ureteroileostomy;

(2) the peritoneal cavity is not opened;

(3) the risks of intestinal anastomosis are avoided;

(4) mucus secretion and absorption of chlorides are absent;

(5) problems with prolapse or retraction of ileal loop are overcome;

(6) competence of anal sphincter need not be considered;

(7) it is possible to catheterize each ureter if desired, a procedure not possible in an ileal conduit.

\section{Acknowledgments}

I should like to express my thanks to Mr D. St Clair L. Henderson for his help and encouragement in the preparation of this paper. I am grateful to Miss Jean McCulloch and everyone at the Department of Medical Photography, Dudley Road Hospital, Birmingham, and to Miss Vivian Barlow for her secretarial help. My thanks to Professor G. Slaney for reading the manuscript and for his advice.

\section{References}

Eckstein, H.B. (1963) Cutaneous ureterostomy. Proceedings of the Royal Society of Medicine, 56, 749.

Eckstein, H.B. \& Kapila, L. (1970) Cutaneous ureterostomy. British Journal of Urology, 42, 306.

Feminella Jr, J.G. \& LAtTimer, J.K. (1971) A retrospective analysis of seventy cases of cutaneous ureterostomy. Journal of Urology, 106, 538.

RickhaM, P.P. (1964) Permanent urinary diversion in childhood. Annals of the Royal College of Surgeons of England, $35,84$.

Straffon, R.A., Kyle, K. \& Corvalan, J. (1969) Technique of cutaneous ureterostomy and results in five patients. Transactions of the American Association of GenitoUrinary Surgeons, 61, 130.

Williams, D.I. \& Rabinovitch, H.H. (1967) Cutaneous ureterostomy for the grossly dilated ureter of childhood. British Journal of Urology, 39, 696. 